\title{
Clube de Leitura O Capítulo que Falta: Conexões entre Tecnologia, Educação e Direitos Humanos
}

\section{${ }^{1}$ Anna Izabel Muniz, ${ }^{2}$ Indiana dos Santos Alves de Souza, ${ }^{3}$ Salete de Fátima Noro Cordeiro}

Faculdade de Educação - Universidade Federal da Bahia (UFBA)- Salvador - BA Brazil.

annaizabelmuniz@gmail.com, indianasantoss10@gmail.com, snoro26@gmail.com

\begin{abstract}
This study describes and analyzes the actions developed by the Reading Club created in a state school to deal with cases of violence and violation of Human Rights that affect students both in physical spaces and in online environments. The Club has been configured as an educational practice of innovation, resistance and authorship. Our goal is to describe the educational practices that take place online, aimed at critical reflection and the construction of citizenship mediated by digital technologies. The methodology used was qualitative, while providing a variety of possibilities for the production and analysis of data. As partial results, we have the strengthening of networks between students and teachers, reading practices and critical reflection and content production.
\end{abstract}

Resumo. Este estudo descreve e analisa as ações desenvolvidas pelo Clube de Leitura criado em uma escola estadual para o enfrentamento dos casos de violência e violação aos Direitos Humanos que atingem os alunos tanto nos espaços físicos, como nos ambientes on-line. O Clube tem se configurado como prática educativa de inovação, resistência e autoria. Nosso objetivo é descrever as práticas educativas que acontecem on-line, voltadas a reflexão crítica e construção da cidadania mediados pelas tecnologias digitais. A metodologia utilizada foi a qualitativa, uma vez que oportuniza uma variedade de possibilidades para a produção e análise de dados. Como resultados parciais, temos o fortalecimento de conteúdos

\section{Introdução}

Iniciamos o ano de 2020 com uma grave crise sanitária que atingiu o planeta. A covid-19 fez o mundo desacelerar por algum tempo, fazendo com que muitos setores da economia e da sociedade tivessem suas atividades total ou parcialmente paralisadas; as pessoas tiveram a necessidade de estar recolhidas em seus lares para evitar o contágio e proliferação da pandemia, incluindo nesse caso, o afastamento das atividades escolares. Segundo dados da UNESCO, até 8 de abril de 2020, vários países haviam efetivado o fechamento de escolas de forma localizada, e mais de 150 países implementaram o fechamento de instituições de ensino em todo o país, representando mais de $90 \%$ dos estudantes do mundo [Pretto et al., 2020]. No Brasil a suspensão das aulas representa milhões de estudantes com interrupção de acesso à educação escolarizada, se formos 
acompanhar os dados do INEP (2019) foram registradas 47,9 milhões de matrículas nas 180,6 mil escolas de educação básica no Brasil, incluindo particulares e públicas, sendo no setor público 38.739.461 matrículas. A suspensão das aulas na rede estadual de ensino da Bahia aconteceu no dia 18 de março e até o presente momento, algumas ações foram tomadas para tentar amenizar o prejuízo sofrido por cerca de 800 mil estudantes (Secom Bahia, 2020), como disponibilização de roteiros de estudo, jogos, sequências didáticas, vídeos e etc. no Portal da Educação (www.educacão.ba.gov.br). Porém não foi implementado, de fato, nenhum tipo de ensino a distância, inviabilizado por diversos motivos, entre eles estão: a falta de infraestrutura de acesso e rede tanto nas escolas como para a maior parte das famílias dos alunos, formação de professores para trabalhar nessa modalidade e inexistência de uma cultura digital nos ambientes escolares.

Assim, o cenário evidencia grandes desafios relativos ao acesso à internet de banda larga, aos dispositivos, já que a maior parte dos acessos, principalmente no que se refere aos alunos, é feita através de dispositivos móveis, que não oferecem as mesmas experiências dos laptops e computadores pessoais. Por parte das escolas e professores junta-se às questões de acesso à infraestrutura e a formação para uso das tecnologias digitais, resultado da falta de investimentos governamentais nesse âmbito, que acaba por dificultar a continuidade das práticas educativas de maneira on-line. Conforme a pesquisa TIC Domicílios 2019, é gritante a desigualdade de acesso à internet entre as classes sociais. Enquanto $99 \%$ das casas da classe A têm acesso à internet (o que corresponde a aproximadamente $15 \%$ da população brasileira), apenas $50 \%$ das casas da classe DE têm acesso. As aulas que devido à pandemia não podem ocorrer presencialmente, também não podem ser obrigatórias na modalidade a distância, visto que essa não seria assegurada nem ao menos para $50 \%$ dos estudantes.

Foi com atenção a este panorama que professoras e estudantes do Centro Estadual de Educação Profissional Isaías Alves (CEEPIA), localizado em Salvador-BA migraram os encontros do Clube de Leitura O Capítulo que Falta para o espaço on-line, o que ocorreu de maneira voluntária e flexível, evidenciando o projeto como um espaço de resistência e engajamento coletivo, que incentiva e fortalece as práticas de conexão em rede.

O objetivo desse artigo é descrever as práticas educativas que acontecem on-line, observando a aproximação dos estudantes com a literatura e discussão dos Direitos Humanos, à medida em que se produz um diálogo interdisciplinar tomando a palavra escrita como base para a produção de saberes coletivos voltados à reflexão crítica e construção da cidadania mediados pelas tecnologias digitais. A metodologia utilizada foi a qualitativa, de modo a formar um elo entre teoria e prática, "pois a realidade abrangida por eles interage dinamicamente, excluindo qualquer dicotomia" [Minayo, 1994, p. 22]. Os instrumentos de produção de dados são a participação nos encontros presenciais e on-line, junto aos dispositivos de pesquisa, que foram as anotações dos encontros nos diários de campo, transcrição e posterior análise dos vídeos gravados. 


\section{O Capítulo que Falta: busca por emancipação e defesa dos Direitos Humanos}

O Clube de Leitura $\mathrm{O}$ Capítulo que Falta nasceu à partir do esforço de duas professoras do CEEPIA ligadas ao Projeto Conexão Escola-Mundo: espaços inovadores para formação cidadã. Esse projeto de autoria de um grupo de pesquisadores da Universidade Federal da Bahia, tem como foco a preocupação com a formação de professores, Direitos Humanos e tecnologias digitais, e concebe os professores da escola como pesquisadores atuando no espaço escolar, este considerado por sua vez, como ambiente de invenção, aprendizagens, criatividade, colaboração e cocriação. Entre os objetivos do projeto Conexão Escola-Mundo está o de fortalecer as escolas e professores para que sejam protagonistas na construção de alternativas ao enfrentamento das problemáticas que têm afetado a escola na contemporaneidade, principalmente através da construção de trajetórias coletivas com o apoio das tecnologias digitais, dentro de uma perspectiva humana e colaborativa.

O projeto Clube de Leitura tem início a partir da parceria entre escola e universidade em 2018, quando através de um amplo diálogo todos os professores foram convidados a construir suas propostas de intervenção e juntarem-se ao projeto acadêmico como pesquisadores e autores de suas propostas. Durante os encontros o corpo docente demonstrou muita preocupação em relação aos casos de violência e violação de direitos humanos, uma constante que atravessava todo o cotidiano escolar tornando-se urgente a busca de alternativas para seu enfrentamento.

O CEEPIA é uma escola de grande representatividade histórica para a cidade, construída no final da década de 30 do século passado, possui arquitetura de espaços generosos e de uma infraestrutura que comporta além da área administrativa, salas de aulas, laboratórios de informática e biblioteca, piscina semi-olímpica, jardins, três anfiteatros um deles ao ar livre, ginásio e quadras de esportes. Segundo Bierrenbach e Cardoso (2018, s/p), “[...] a escola deveria contar com espaços aptos para ampliar a formação dos estudantes. Assim, foram propostos espaços para a realização de cursos de educação artística, científica e física, além de outros dedicados à socialização dos estudantes." O que ressalta que o pensamento de seus idealizadores pretendiam a construção de um espaço que não apenas garantisse vagas escolares, mas que colaborasse para a formação cidadãos em uma sociedade que estava em transformação, algo que as políticas públicas atuais têm tentado soterrar.

O CEEPIA atende o público jovem que provém de diversos bairros da capital oferecendo as modalidades Educação de Jovens e Adultos (EJA) e Educação Profissional: Formação Técnica Subsequente e Educação Profissional Integrada, atendendo à 2.016 estudantes nos três turnos de funcionamento em 2019. Essa característica de trabalhar de forma majoritária com a juventude, tanto tem contribuído para que se escancarem os problemas sociais e que atingem principalmente o público jovem, como também para que se busquem alternativas para o enfrentamento desses mesmos problemas através de uma perspectiva educativa emancipadora e crítica. Um dos problemas a serem enfrentados foi a violência tanto nas redes sociais como na escola evidenciadas nos discursos de intolerância, racismo, preconceito, LGBTfobia, gordofobia, bullying e ciberbullying, e uma preocupante ausência do entendimento de 
Direitos Humanos não só por parte dos alunos, mas da comunidade escolar como um todo. Abordar então esses aspectos de maneira educativa sob o prisma dos direitos humanos levou à uma metodologia aberta, livre, dialogada e mediada através da literatura.

Temos no Brasil o Plano Nacional de Educação em Direitos Humanos (PNEDH), política pública que visa construir uma cultura de Direitos Humanos. A Educação em DH adquire um sentido amplo, de formação integral do ser humano e sua formação para a cidadania. Lapa, Gusso e Souza (2018) elucidam três aspectos e seus desafios sobre a Educação em DH: acesso, permanência e conteúdo; deixando nítido que precisa existir a garantia do acesso à educação, da permanência integral ao sistema educacional como um todo e a diversificação do conteúdo, para que este seja passível de entendimento para todos.

Durante os encontros do Clube, as leituras foram selecionadas através de uma curadoria (por estudantes e professores) para que tocassem em questões como racismo, machismo, LGBTfobia e outros assuntos que os mesmos sentiam necessidade de discutir e compartilhar experiências. O que se pretende através dos encontros é desenvolver não só o potencial de leitura e escrita dos alunos, mas também o desenvolvimento dos jovens para que sejam fortalecidos e consigam se posicionar diante das narrativas que vão encontrando em seu cotidiano. Além da literatura, o Clube também estimula o compartilhamento de filmes, séries televisivas, e a arte em seus diversos formatos como pontos de ancoragem para desenvolver práticas de formação colaborativa, aprendizagens significativas e estimular a criatividade e inovação. Em decorrência dessa metodologia os alunos não têm apenas consumido conteúdos literários, mas estão produzindo de maneira autoral seus próprios conteúdos em diversas linguagens possibilitadas pelo digital.

\section{Encurtando as distâncias e estimulando a autoria}

O Clube de Leitura foi concebido para existir dentro de uma proposta presencial, realizado inicialmente em salas de aulas disponíveis onde eram improvisados colchonetes ou esteiras para acomodação de alunos e professores e em seguida, migrou para a biblioteca da escola, como estratégia de dar visibilidade a esse espaço, que é pouco frequentado pelos alunos. Desde o início de 2020, com a necessidade de recolhimento para garantia da saúde e da vida, e com a consequente suspensão das aulas, o Clube migrou para os espaços on-line. Como desdobramento dessa opção os encontros acontecem de forma virtual através da plataforma MConf, uma plataforma de transmissão desenvolvida em software livre pela Rede Nacional de Pesquisa (RNP) e que tem suporte no STI da UFBA. A plataforma possibilitou que os estudantes que não tinham notebook pudessem acessar as reuniões em seus celulares através de link sem necessidade de baixar app. Também foram utilizadas redes sociais e mensageiros instantâneos para comunicação do grupo e publicação dos conteúdos.

De acordo com um estudo que mede os hábitos e comportamento de usuários da internet brasileira pelo Centro Regional de Estudos para o Desenvolvimento da Sociedade da Informação (Cetic.br) do Núcleo de Informação e Coordenação do Ponto BR (NIC.br), revelou que o Brasil tem 126,9 milhões de pessoas conectadas à internet, com $56 \%$ se conectando apenas pelo celular. Assim os ambientes escolhidos foram 
aqueles que pudessem ser suportados pelos dispositivos móveis, smartphones, pois esse é o principal recurso utilizados para a participação nos encontros. Com essa opção foi possível que professores e estudantes continuassem em rede, trabalhando, discutindo e produzindo conteúdos. Bonilla e Oliveira (2011) trazem as redes como estruturantes para as comunidades de interação, as quais constituem as comunidades de conhecimento e produções colaborativas.

Com o on-line, as distâncias se estreitaram a cada encontro. Percebemos estudantes que antes não tinham a oportunidade de participar presencialmente em decorrência do choque de horários com outras atividades ou em função dos distanciamentos físicos, têm a oportunidade de se aproximar. Através de ajustes e troca de horários, buscamos conseguir o maior número de estudantes participando. Além disso percebemos a participação da comunidade no clube em sua versão on-line, que são amigos e parentes dos primeiros integrantes, bem como alunas de diferentes cursos da UFBA e UNEB que têm participado e tornado mais ricas as trocas de saberes interdisciplinares.

Como a predominância das atividades nos ambientes virtuais, muitos participantes começam a socializar suas produções acerca do que leem e discutem. Temos produções no formato de vídeos com leituras e poesias; produção de escritos como contos, poesias, colagens, diversos formatos de remix, etc. É por meio das interações que redes criativas e colaborativas são criadas, e a troca de ideias em rede favorece a inovação. A autoria, de acordo com Veloso (2014), depende de que tais redes tenham algumas características, como um nível de abertura que permita a fluidez necessária às mudanças que podem aparecer. As professoras envolvidas no processo atuam como hackers, atuando com paixão e entusiasmo pelo que fazem. Para Pretto (2010), "podemos considerar que, de fato, o hacker pode ser qualquer profissional que atue de forma entusiasmada na sua profissão" e não necessariamente um entendido em códigos de computador. Consideramos as professoras hackers pois criaram brechas no sistema da escola que se mostra sempre austero ao diferente, e continuaram esse protagonismo no momento de pandemia e isolamento físico. Sua recompensa tem sido o prazer de compartilhar o que sabem e trabalhar de maneira colaborativa. Suas ações abrem caminho para que os estudantes pensem de maneira crítica e autônoma, construindo e fortalecendo suas identidades. Chama atenção no decorrer da pesquisa o desenvolvimento dos participantes, principalmente os estudantes que ganham desenvoltura em expressar suas opiniões, fazendo diversas relações não só com suas vivências pessoais, como também com acontecimentos históricos e ressignificando-as de suas narrativas.

\section{CONCLUSÃO}

O Clube do Livro passa a ocupar lugar de resistência e enfrentamento aos desafios trazidos pela violência e luta por Direitos Humanos, tais como incitamento ao discurso de ódio nas redes sociais, racismo, machismo, gordofobia, misoginia e outros. As tecnologias estão presentes encaradas em sua ambiguidade, mas incorporadas como aliadas nesse processo, compreendidas como estruturantes de processos mais horizontalizados e autorais e não somente um instrumento de transposição da educação escolar para a tela dos dispositivos. Os encontros demonstram o poder dos afetos, da 
responsabilidade social e do engajamento dos participantes, sejam professores, bolsistas, estudantes ou funcionários, como evidências de que podemos construir e produzir conhecimentos colaborativos, abertos e livres.

\section{Referências}

Bierrenbac, A. C. S; Cardoso, L. A. F (2018). . O Instituto Isaías Alves (ICEIA): arquitetura educação na modernização soteropolitana. Anais do $7^{\circ}$ DOCOMOMO Norde-Nordeste. Manaus.

Bonilla, M. H. S., and Oliveira, (2011) P.C.S. Inclusão digital: ambigüidades em curso. Bonilla, M. H. S., and PRETTO, N. D. L., orgs. Inclusão digital: polêmica contemporânea [online]. Salvador: EDUFBA, p. 23-48. 978-85-232-1206-3. Available from SciELO Books.

CGI, Comitê Gestor da Internet no Brasil. Pesquisa sobre o Uso das Tecnologias da Informação e da Comunicação nos domicílios brasileiros: TIC Domicílios 2019. São Paulo: Comitê Gestor da Internet no Brasil, 2019. Disponível em: https://www.cetic.br/pt/pesquisa/domicilios/indicadores/. Acesso em: 10 de junho 2020 .

Lapa, F. B.; Gusso, L. C. S; Souza,(2018) S. Direito humano à educação (art. 26 na DUDH): os desafios para implementar uma educação em Direitos Humanos no Brasil. In: Revista Diálogo, n. 38.

Minayo, M. C. de S. (org.), (2002). Pesquisa Social. Teoria, método e criatividade. 21 ed. Petrópolis: Vozes.

Pretto, N. D. L. (2010) Professores Universitários em rede: um jeito hacker de ser. Motrivivência, n. 34, p. 156-169.

Pretto, N. D. L., (2020) et. al. Educação em tempos de pandemia: Reflexões sobre as implicações do isolamento físico imposto pela COVID-19. Disponível em: https://blog.ufba.br/gec/?page_id=3298. Acesso em: 2 de jun. 2020.

Veloso, M. M. S. de A. (2014) O professor e a autoria no contexto da cibercultura: redes da circulação no cotidiano da escola / Maristela Midlej Silva de Araújo Veloso. (Tese) - Salvador. 